\title{
Low frequency vocalizations attributed to sei whales (Balaenoptera borealis)
}

\author{
Mark F. Baumgartner \\ Biology Department, Woods Hole Oceanographic Institution, Woods Hole, Massachusetts 02543 \\ Sofie M. Van Parijs and Frederick W. Wenzel \\ Northeast Fisheries Science Center, 166 Water Street, Woods Hole, Massachusetts 02543 \\ Christopher J. Tremblay \\ Bioacoustics Research Program, Cornell University, 159 Sapsucker Woods Road, Ithaca, New York 14850 \\ H. Carter Esch \\ Biology Department, Woods Hole Oceanographic Institution, Woods Hole, Massachusetts 02543 \\ Ann M. Warde \\ Bioacoustics Research Program, Cornell University, 159 Sapsucker Woods Road, Ithaca, New York 14850
}

(Received 15 February 2008; revised 2 May 2008; accepted 19 May 2008)

\begin{abstract}
Low frequency $(<100 \mathrm{~Hz})$ downsweep vocalizations were repeatedly recorded from ocean gliders east of Cape Cod, MA in May 2005. To identify the species responsible for this call, arrays of acoustic recorders were deployed in this same area during 2006 and $2007.70 \mathrm{~h}$ of collocated visual observations at the center of each array were used to compare the localized occurrence of this call to the occurrence of three baleen whale species: right, humpback, and sei whales. The low frequency call was significantly associated only with the occurrence of sei whales. On average, the call swept from 82 to $34 \mathrm{~Hz}$ over $1.4 \mathrm{~s}$ and was most often produced as a single call, although pairs and (more rarely) triplets were occasionally detected. Individual calls comprising the pairs were localized to within tens of meters of one another and were more similar to one another than to contemporaneous calls by other whales, suggesting that paired calls may be produced by the same animal. A synthetic kernel was developed to facilitate automatic detection of this call using spectrogram-correlation methods. The optimal kernel missed $14 \%$ of calls, and of all the calls that were automatically detected, 15\% were false positives. (C) 2008 Acoustical Society of America.
\end{abstract}

[DOI: 10.1121/1.2945155]

PACS number(s): 43.80.Ka [WWA]

Pages: 1339-1349

\section{INTRODUCTION}

Passive acoustic monitoring has matured into a powerful tool for both research and conservation by allowing persistent observations of marine mammal occurrence over larger spatial scales and longer time scales than previously possible with traditional visual assessment methods. Recordings of baleen whale vocalizations have been used to assess abundance (George et al., 2004), seasonal occurrence (Stafford et al., 2001; Heimlich et al., 2005; Mellinger et al., 2007), distribution (Stafford et al., 2001; Heimlich et al., 2005), and behavior (Croll et al., 2002; Darling et al., 2006; Oleson et al., 2007; Stimpert et al., 2007). These studies rely on very fundamental information about which species produce particular calls. Remarkably, many calls produced by marine mammals have yet to be described and attributed to an individual species, likely because systematic collection of acoustic and visual observations to confirm the species of calling whales is uncommon, and tagging studies that use acoustic recording instrumentation have been limited to a few species (Matthews et al., 2001; Madsen et al., 2002; Zimmer et al., 2005; Johnson et al., 2006; Oleson et al., 2007; Stimpert et al., 2007).

Sei whales (Balaenoptera borealis) are found primarily in the temperate oceans of both the northern and southern hemispheres, and apparently migrate between lower latitude winter breeding grounds and higher latitude summer feeding grounds (Mizroch et al., 1984; Perry et al., 1999). They feed primarily on aggregations of copepods, euphausiids, and small schooling fish by filtering these prey through their baleen (Hjort and Ruud, 1929; Kawamura 1974; Flinn et al., 2002). The acoustic behavior of sei whales, like most aspects of their behavior and ecology, is quite poorly described. Only four reports of sei whale calls are currently available. Thompson et al. (1979) described recordings of sei whales obtained in the waters between Nova Scotia and Newfoundland, Canada, as $0.7 \mathrm{~s}$ long bursts of seven to ten metallic pulses with peak energy at $3 \mathrm{kHz}$. Knowlton et al. (1991) described similar 1.4-2.6 s midfrequency vocalizations recorded in waters off southwestern Nova Scotia, Canada that consisted of two bouts of 10-20 frequency-modulated (FM) $1.5-3.5 \mathrm{kHz}$ sweeps separated by $0.4-1 \mathrm{~s}$. In the Southern Ocean near the Antarctic Peninsula, McDonald et al. (2005) recorded a number of tonal, FM, and broadband calls between 200 and $700 \mathrm{~Hz}$ in proximity to sei whales. The estimated source level of these calls was relatively low for baleen whales $(156 \mathrm{~dB}$ with regard to $1 \mu \mathrm{Pa}$ at $1 \mathrm{~m})$, and 


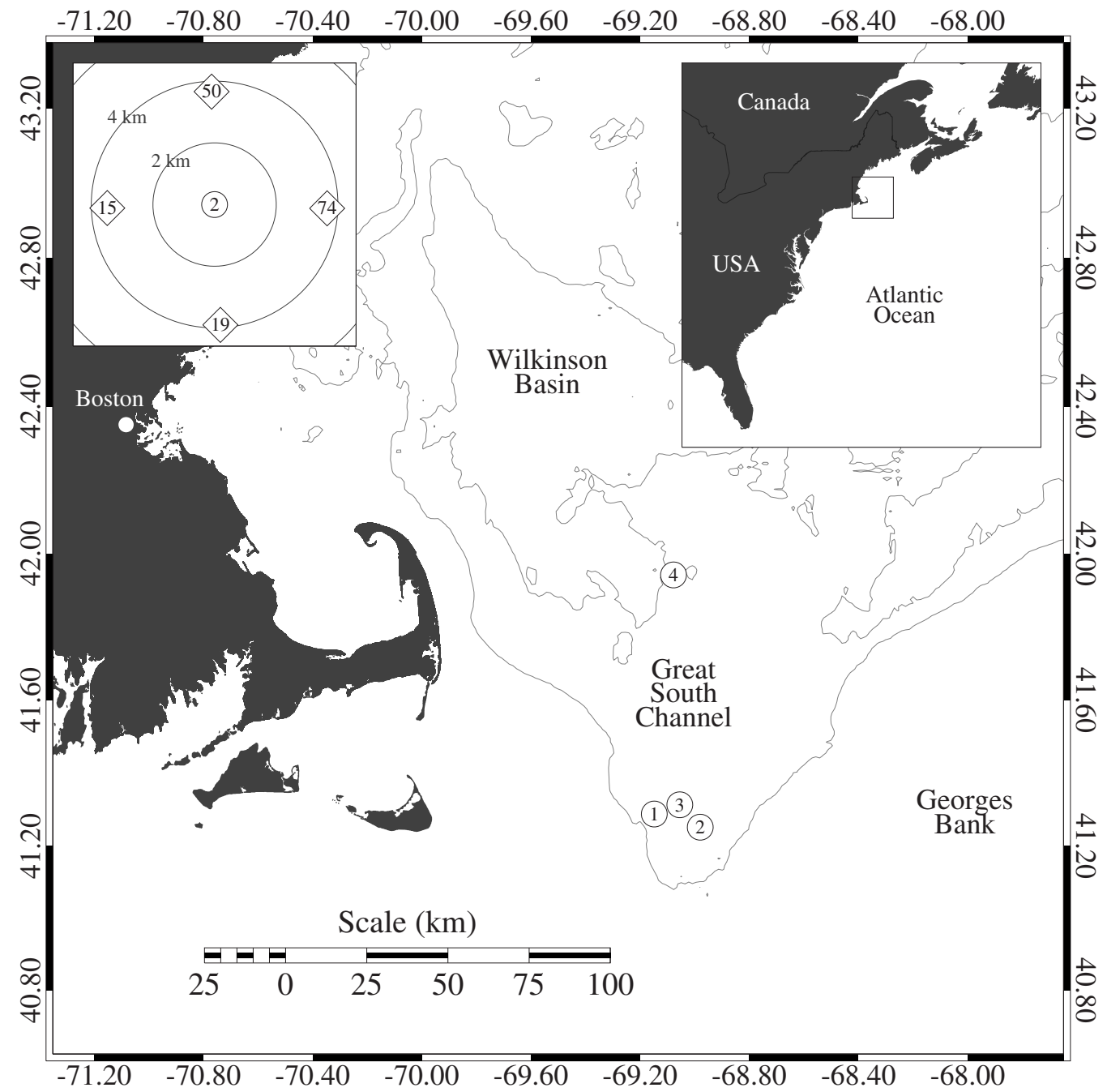

FIG. 1. Locations of the four anchor stations in the Great South Channel. The inset at the upper left depicts the configuration of MARU Nos. 15, 19, 50, and 74 around anchor station 2 .

McDonald et al. (2005) suggested the calls were likely used for communication over short distances (a few kilometers) to facilitate feeding or social interactions with nearby conspecifics. Finally, Rankin and Barlow (2007) recorded two low frequency calls near sei whales just north of the Hawaiian Islands: a FM sweep from 100 to $44 \mathrm{~Hz}$ lasting $1.0 \mathrm{~s}$, and a lower frequency FM sweep from 39 to $21 \mathrm{~Hz}$ lasting $1.3 \mathrm{~s}$.

This paper describes a low frequency downsweep call attributed to sei whales in the northwestern Atlantic Ocean that is similar to the $100-44 \mathrm{~Hz}$ downsweep call recorded by Rankin and Barlow (2007) in the Pacific Ocean. We initially detected this call in acoustic recordings collected by autonomous ocean gliders off the coast of Cape Cod, MA during May 2005 (Fratantoni and Baumgartner, 2005; Baumgartner et al., 2006; Baumgartner and Fratantoni, in press), and subsequently designed the current study to identify the species producing the call. Acoustic data were collected from an array of recorders deployed in an area frequented by right $(E u-$ balaena glacialis), sei, and humpback (Megaptera novaeangliae) whales during the spring. Species confirmation of the downsweep call was accomplished by comparing the occurrence of these species to the occurrence of localized calls during $70 \mathrm{~h}$ of collocated visual and acoustic observations.
Finally, a synthetic kernel (a mathematical representation of a call in frequency-time space) was developed to aid in the automated detection of the downsweep call in future studies via spectrogram cross correlation.

\section{METHODS}

\section{A. Acoustic and visual observations}

Collocated visual and acoustic observations were collected on four separate occasions during the spring seasons of 2006 and 2007 in the Great South Channel between Cape Cod, MA and Georges Bank (Fig. 1; Table I). For each study, observations were collected in the vicinity of a fixed geographic location called an anchor station. Initial visual surveys were conducted prior to each study to find an area of high baleen whale abundance; the anchor station was then established in this area. The primary focus of these surveys was to study the ecology of North Atlantic right whales; therefore, areas with high abundances of right whales were preferentially sought.

Acoustic recordings were collected with recoverable marine autonomous recording units (MARUs), moored instruments designed by and leased from Cornell University 
TABLE I. Summary of each anchor station study, including starting date and time (local time), duration of recorder deployments, time that the anchor station was occupied by the NOAA Ship Albatross IV (time in parentheses indicates the duration of visual effort during daylight hours), and water depth at the anchor station.

\begin{tabular}{|c|c|c|c|c|}
\hline $\begin{array}{l}\text { Anchor } \\
\text { station }\end{array}$ & Start date/time & $\begin{array}{c}\text { Recorder } \\
\text { deployments } \\
\text { (h) }\end{array}$ & $\begin{array}{l}\text { Station occupied } \\
\text { (h) }\end{array}$ & Water depth (m) \\
\hline 1 & $5 / 7 / 06 \quad 13: 30$ & 25.5 & $21.0(15.5)$ & 103 \\
\hline 2 & 5/23/06 15:30 & 39.0 & $34.5(18.5)$ & 137 \\
\hline 3 & 5/21/07 19:00 & 41.5 & $37.5(17.0)$ & 160 \\
\hline 4 & 6/6/07 20:00 & 48.0 & $35.5(19.0)$ & 192 \\
\hline
\end{tabular}

Laboratory of Ornithology's Bioacoustics Research Program. Each MARU consists of a digital audio recorder, hard drive, and batteries encased within an 18 in. glass sphere that is positively buoyant, vacuum sealed, and rated to a depth of $6700 \mathrm{~m}$. Raw audio is captured with an HTI-94-SSQ series hydrophone $(2 \mathrm{~Hz}-30 \mathrm{kHz}$ frequency response) and internal preamplifier (combined maximum sensitivity of $-165 \mathrm{~dB}$ with regard to $1 \mathrm{~V} / \mu \mathrm{Pa}$ ) mounted outside the plastic "hard hat" that protects the glass sphere. The MARUs were programed to sample at $10 \mathrm{kHz}$ for our study, and the resulting digital audio data were low-pass filtered and decimated to $2048 \mathrm{~Hz}$ to facilitate analysis of low frequency baleen whale calls. Prior to the start of each anchor station study, four MARUs were deployed from the NOAA research vessel $\mathrm{Al}$ batross $I V$ in a diamond configuration approximately $3.7 \mathrm{~km}$ (2 nautical miles) away from the central anchor station (Fig. 1). The MARUs were moored with sandbags so that they floated 1.5-2 $\mathrm{m}$ above the seafloor. The buoys were recovered 25.5-48 h after deployment (Table I) by acoustically triggering the MARU's release mechanism.

After the MARUs were deployed, the R/V Albatross IV continuously occupied the central anchor station for a period between 21.0 and $37.5 \mathrm{~h}$ (Table I) to systematically estimate whale abundance and collect continuous environmental observations. The ship was not actually anchored at the station; instead, the ship was moved to the station immediately prior to the start of each half-hourly observation period (i.e., at the top and bottom of the hour), and then allowed to drift off the station during the ensuing 15-20 min (drift from the station was typically $\sim 500 \mathrm{~m}$ ). During daylight hours, rotating teams of observers noted the location of all cetaceans within visual range. Three observers cooperatively scanned $360^{\circ}$ around the ship using the naked eye and handheld $7 \times 50$ binoculars for 15 min every half hour (i.e., from 0 to $15 \mathrm{~min}$ past the hour and from 30 to $45 \mathrm{~min}$ past the hour) and for each group of cetaceans observed, recorded (1) the species, (2) group size, (3) distance and relative bearing from the ship to the group, and (4) behavioral observations. Care was taken to avoid recounting individuals or groups during a $15 \mathrm{~min}$ observing period. Oceanographic measurements and zooplankton abundance were collected at half-hourly intervals around the clock at the anchor station using an instrument profiler consisting of a conductivity-temperature-depth instrument, a fluorometer, a video plankton recorder, and an optical plankton counter; however, those data were collected for a different study and are not presented here.

To confirm the identity of the species producing low frequency downsweep calls, the occurrence of these calls was compared to the occurrence of the most abundant baleen whale species observed during the anchor station studies (right, sei, and humpback whales). All calls were localized (see below) so that only calls within $3 \mathrm{~km}$ of the anchor station were compared to the sighting data (the visual detection range from the ship was approximately $3 \mathrm{~km}$ for accurate species identification). Since the downsweep calls were not particularly numerous within this $3 \mathrm{~km}$ radius of the ship, a sampling unit was defined as $1 \mathrm{~h}$ of collocated visual and acoustic observations. The presence of whales was therefore noted for each sampling unit by combining the results of two successive observing periods (e.g., humpback whale presence would be noted for the sampling unit starting at 13:52:30 and ending at 14:52:30 if one or more humpback whales were sighted during either the 14:00-14:15 or the 14:30-14:45 observing periods). Sampling units with only one observing period (near dawn or dusk) were used in the analysis only if whales were present during that observing period. The presence of calls was also noted for each sampling unit, and a two-way contingency table was constructed for each species to compare the presence of whales to the presence of calls. The Cramér, or phi, coefficient (Sokal and Rohlf, 1995) was used to determine the degree of the association between the occurrence of whales and calls. This statistic varies from -1 to 1 to indicate the extent of negative or positive association, and is analogous to the correlation coefficient. Finally, a one-way Fisher's exact test was used to examine the null hypothesis that call occurrence was independent of whale presence against an alternative hypothesis that call occurrence was positively associated with whale presence.

\section{B. Detector development}

To facilitate automated detection of the downsweep call, we built a synthetic kernel that could be cross correlated with spectrograms of audio data to reliably identify call times. The methods to construct and ultimately use the kernel were based on the work of Mellinger and Clark (2000). Exemplars of the downsweep call with a high signal to noise ratio ( $n$ $=60$ ) were extracted from acoustic recordings collected in the Great South Channel by autonomous underwater vehicles (ocean gliders) in 2005 (Fratantoni and Baumgartner, 2005; Baumgartner et al. 2006; Baumgartner and Fratantoni, in press). Spectrograms of each exemplar were normalized, synchronized, and then averaged to produce a single representation of the downsweep call [Fig. 2(a)]. A family of detector kernels was produced from this average call and then evaluated to determine which kernel had the best performance characteristics.

Individual kernels were constructed using different amplitude contours of the averaged call (Fig. 2). For time $t$ in the spectrogram, the start and end frequencies, $f_{0}$ and $f_{1}$, of the amplitude contour were determined. From these, two parameters were defined: 


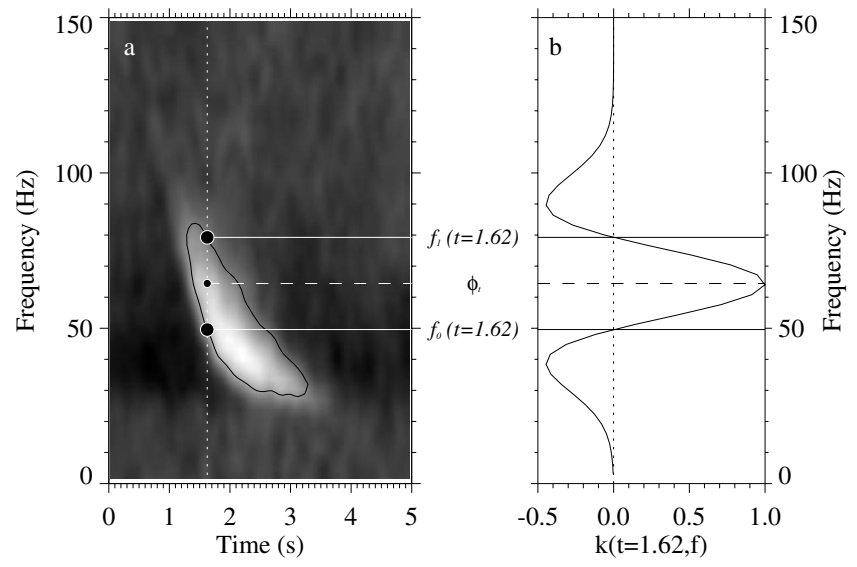

FIG. 2. (a) Spectrogram representing the average of 60 downsweep call exemplars. A single contour is shown to illustrate the construction of a kernel detection function. The large filled black circles indicate the start $\left(f_{0}\right)$ and end $\left(f_{1}\right)$ frequencies of the contour at time $t=1.62 \mathrm{~s}$, and the small filled black circle indicates the midpoint of these frequencies $\left(\phi_{t}\right)$. (b) The kernel detection function at $t=1.62 \mathrm{~s}$ with $f_{0}$ and $f_{1}$ indicated as solid horizontal lines, and $\phi_{t}$ indicated as a dashed horizontal line.

$$
\phi_{t}=\frac{1}{2}\left[f_{0}(t)+f_{1}(t)\right]
$$

and

$$
\sigma_{t}=\frac{1}{2}\left[f_{1}(t)-f_{0}(t)\right]
$$

The kernel was then defined [after Mellinger and Clark (2000)] as

$$
k(t, f)=\left(1-\frac{\left(f-\phi_{t}\right)^{2}}{\sigma_{t}^{2}}\right) e^{-\left(f-\phi_{t}\right)^{2} /\left(2 \sigma_{t}^{2}\right)} .
$$

This approach to kernel construction is quite similar to that described by Mellinger and Clark (2000); however, they used linear sections to approximate the shape of a call (i.e., successive values of $\phi_{t}$ fall along a line in frequency-time space) whereas our approach attempts to incorporate any nonlinearity present in the call shape (i.e., $\phi_{t}$ is allowed to vary freely according to the average call contours).

Putative vocalizations were detected by first creating spectrograms of the audio data using short-time Fourier transforms for each 640 sample frame (0.3125 s) with $80 \%$ overlap and a Hann window. Continuous quasitonal noise (e.g., ship noise) was removed using a $10 \mathrm{~s}$ median filter on each frequency band in the spectrogram. The synthetic kernel was then cross correlated with the spectrogram and the resulting time series of correlation coefficients was considered a detection function (Fig. 3). Mellinger and Clark (2000) used a spectrogram covariance approach; however, the spectrogram correlation method was used in this study because it accounts for changes in gain between different types of instruments (e.g., between MARUs and glider recorders). The spectrogram correlation is equivalent to the spectrogram covariance normalized by the variability in the audio data (which, in turn, is a function of gain). Peaks in the detection function indicate times of putative calls, and the amplitude of the peaks indicates the amount of agreement between the putative call and the kernel. Automated detection is accomplished by isolating only those peaks that exceed a predetermined threshold.
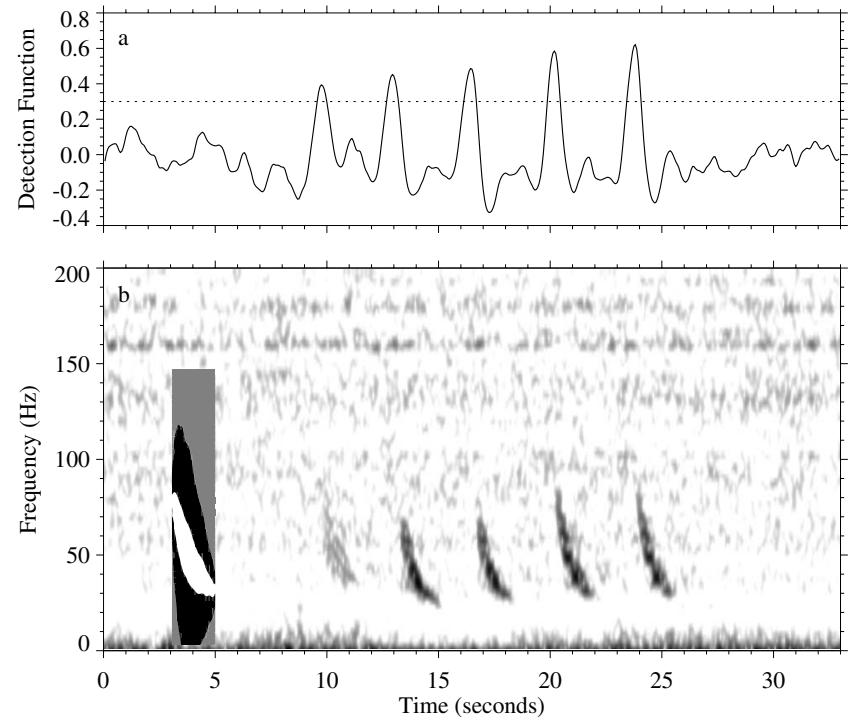

FIG. 3. (a) An example of a detection function (spectrogram-kernel correlation coefficient) derived from the spectrogram in (b). The synthetic kernel that was used to derive the detection function in (a) is shown at the left in (b) (shading indicates the sign of the kernel: white=positive, black $=$ negative, gray $=0$ ). If a detection threshold of 0.3 was used to isolate calls [dotted line in (a)], then five peaks are present corresponding to the calls in (b). These calls consist of an initial faint call followed by two pairs of calls generated by different animals to the northeast (faint call), south (first pair), and the southeast (second pair) of the MARU array.

The performance of all the kernels was evaluated by first detecting all downsweep calls in the acoustic record of one of the buoys deployed during the study at anchor station 1 (buoy No. 15). This was accomplished by both manual review and an assisted review with a preliminary kernel detector and a very low detection threshold. The assisted review was necessary because the independent manual review missed a substantial number of calls (see Sec. III). Two experienced reviewers independently scanned spectrograms of the audio data, isolated times of low frequency downsweep calls, and confirmed the calls aurally. The independent reviews were combined to produce a single dataset of confirmed downsweep calls. The assisted review automatically identified times of potential downsweep calls using a preliminary kernel, and then each call was evaluated by a third independent reviewer. Calls from the manual review and from the assisted review were compared to evaluate the efficiency of these two approaches. Finally, all confirmed calls were used to evaluate the family of kernel detectors and to select the one with the best performance characteristics. Detection performance was evaluated for each kernel by comparing the percentage of false detections to the percentage of missed calls (traditional receiver-operator characteristic curves cannot be constructed with these data because true negatives cannot be enumerated).

\section{Localization}

The positions of vocalizing whales were estimated from the differences in arrival times of calls at the four MARUs deployed around each anchor station. Immediately before deployment and again after recovery of the MARUs, an impulsive sound (e.g., banging a pipe with a wrench) was simul- 
taneously recorded by each of the instruments; during postprocessing, each recorder was synchronized to a common time base using these impulsive sounds. Differences in arrival times were estimated by spectrogram cross correlation. Briefly, a detected call in the spectrogram for one buoy was cross correlated with the spectrograms of the other buoys within \pm 10 s of the detection time. Peaks in the crosscorrelation functions indicated the possible presence of the same call in the other buoy recordings, and manual verification was necessary to exclude spurious matches. The lead or lag time of the cross correlation is an estimate of the time difference of arrival. Locations could be estimated when calls were detected on three or four of the recorders using equations adapted from Watkins and Schevill (1971). In cases where calls could be detected on all four of the recorders, an iterative refinement technique was also used to minimize measurement errors in the time differences of arrival [after Foy (1976) and Freitag et al. 2001]. Baumgartner et al. (in press) described the details of this localization and iterative refinement approach in the context of tracking baleen whales tagged with an acoustic transmitter. The exact same localization methods described by Baumgartner et al. (in press) are used here with the assumption that the whale vocalizes near the surface (Matthews et al., 2001; Oleson et al., 2007).

\section{RESULTS}

\section{A. Call description}

Only high-quality (i.e., high signal to noise ratio), low frequency downsweep calls were analyzed for call characteristics ( $n=108$ calls produced within $2 \mathrm{~km}$ of each MARU during all anchor station studies). On average, these calls swept from a starting frequency of $82.3 \mathrm{~Hz}(\mathrm{SD}=15.2 \mathrm{~Hz})$ to an ending frequency of $34.0 \mathrm{~Hz}(\mathrm{SD}=6.2 \mathrm{~Hz})$ over $1.38 \mathrm{~s}$ $(\mathrm{SD}=0.37 \mathrm{~s})$ (Fig. 4). Calls farther away from the recorders tended to have lower starting frequencies (correlation between distance from recorder and starting frequency: $r=$ $-0.375, p<0.0001$ ) and were shorter in duration (correlation between distance from recorder and call duration: $r=$ $-0.260, p=0.007)$, which is consistent with attenuation of the higher frequencies at the beginning of the call for distant vocalizations. Variability in call characteristics was largely driven by changes in the start frequency; the ending frequency was considerably less variable, and duration, slope (end minus start frequency divided by duration), and sweep (start minus end frequency) covaried significantly with start frequency (duration: $r=0.434, p<0.001$, slope: $r=-0.622$, $p<0.001$; sweep: $r=0.916, p<0.001$ ).

Calls occasionally occurred in pairs [Fig. 4(b)], and for those pairs localized inside the array, the average distance between position estimates for each individual call comprising the pair was $66 \mathrm{~m}(\mathrm{SD}=47 \mathrm{~m}, n=14$ pairs localized within $3.7 \mathrm{~km}$ of the anchor station during all anchor station studies). Although positional error in the localization procedure was not directly evaluated, it was likely on the order of several tens of meters. Similarity between the first and last calls in the pairs was compared to the similarity between the first call in each pair and contemporaneous calls made by
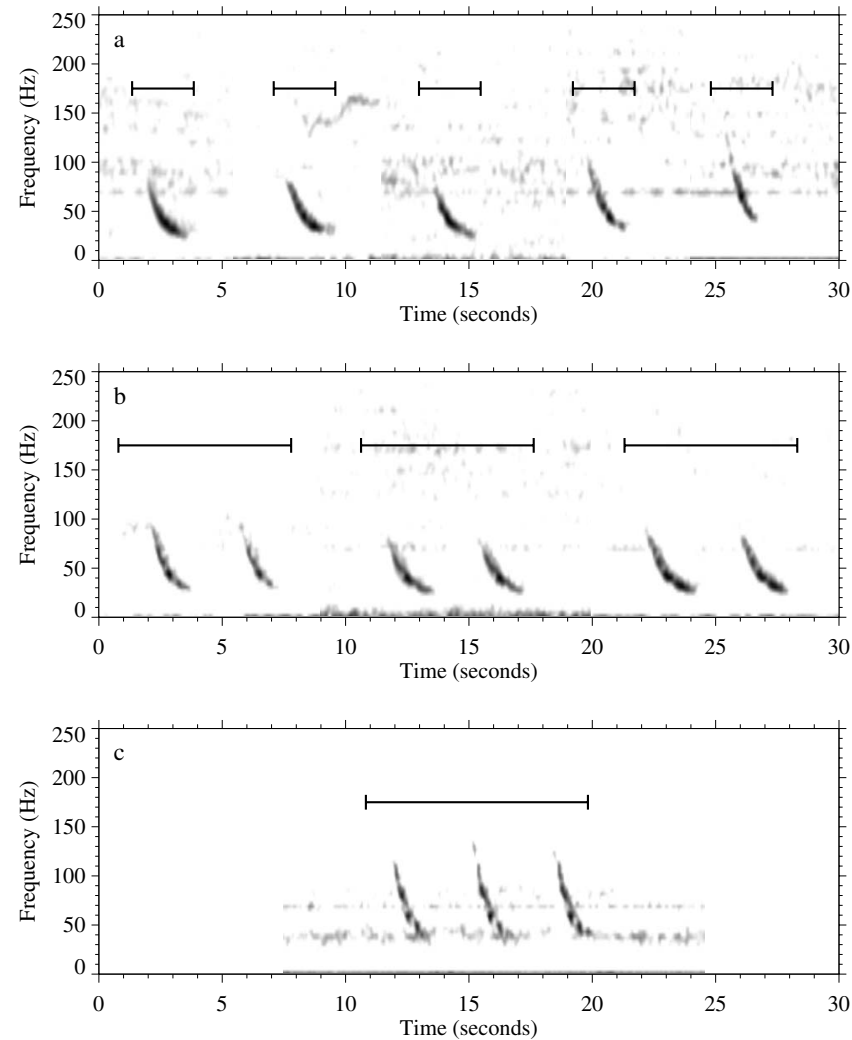

FIG. 4. Examples of low frequency downsweep calls occurring in (a) singles, (b) pairs, and (c) triplets. The bars indicate individual calls or sets of calls. Each single in (a) and pair in (b) were recorded at different times on different recorders and concatenated here (i.e., calls were not recorded contiguously as shown).

other whales in the area; similarity was measured as the correlation between call spectrograms. Only contemporaneous calls that could not have been produced by the whale making the first call in a pair were used (i.e., only calls produced sufficiently far apart that a whale would have to travel at an unrealistic speed of over $15 \mathrm{~m} \mathrm{~s}^{-1}$ to produce both the paired call and the contemporaneous call). Each of the 14 call pairs detected within $3.7 \mathrm{~km}$ of the anchor stations had between zero and ten contemporaneous calls available for comparison (one pair was omitted because of a low signal to noise ratio). Of the 40 resulting comparisons, we found only one case in which the correlation coefficient between the first call in a pair and a contemporaneous call was significantly higher than the corresponding correlation coefficient between the two calls comprising that pair $(p<0.05$, one-sided z-test for comparing correlation coefficients, no adjustment for multiple testing). These results indicate that the calls comprising the pairs were more similar to one another than to calls produced by other whales nearby. Based on this similarity and the short distance between calls comprising the pairs, we presume that call pairs are produced by the same individual whale. The average interval between individual calls in a pair, measured from the start of the first call to the start of the second call, was $3.5 \mathrm{~s}(\mathrm{SD}=0.36, n=112$ pairs localized inside or outside the array during all anchor station studies). On rare occasions, triplets were recorded [Fig. 4(c)] with similar intercall intervals as the pairs. 

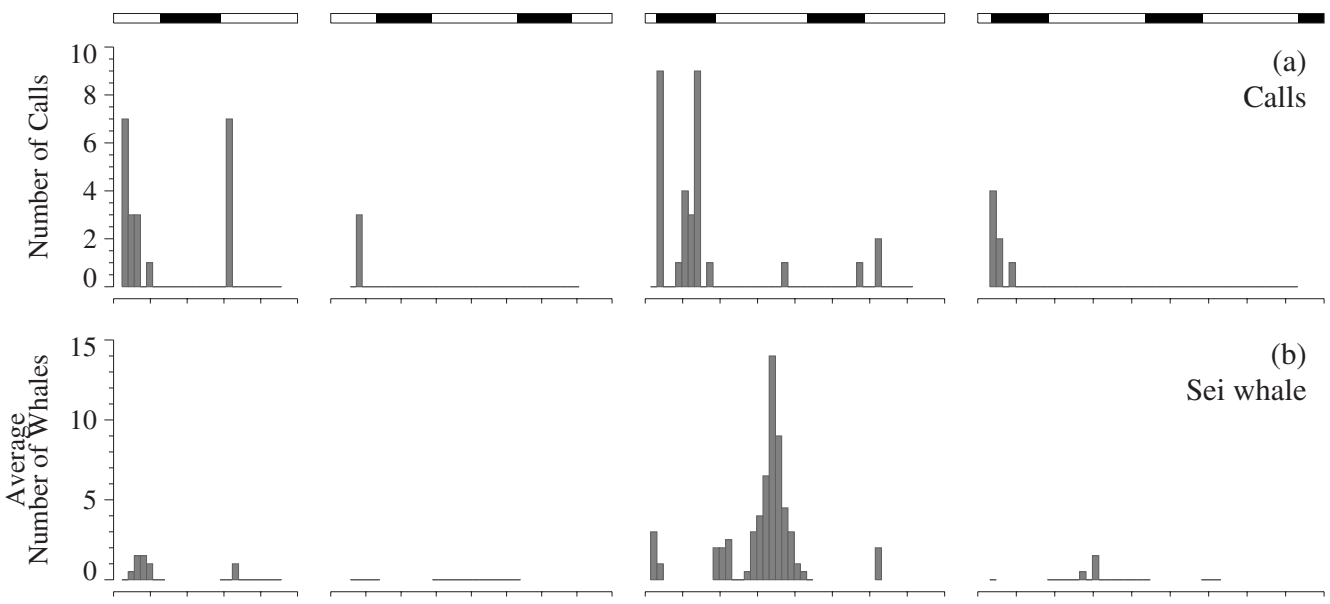

(b)
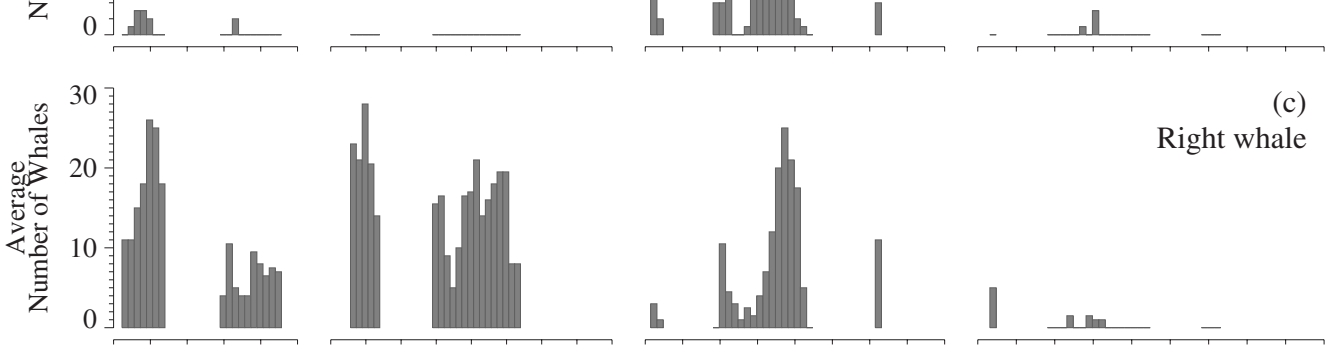

(c)

Sei whale

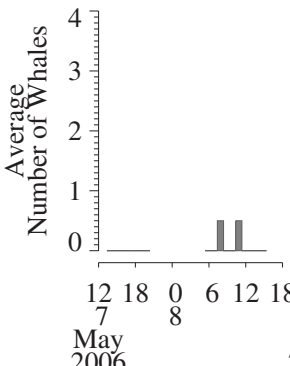

Station 1
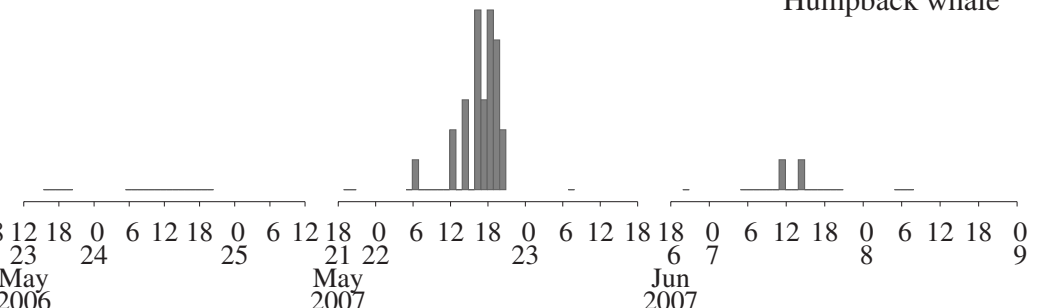

Station 2

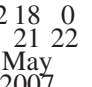

May

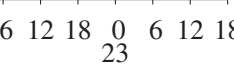

Station 3

Station 4

FIG. 5. Hourly time series of (a) downsweep calls detected and localized within $3 \mathrm{~km}$ of the anchor station and [(b)-(d)] average whale abundance for (b) sei, (c) right, and (d) humpback whales within $3 \mathrm{~km}$ of the anchor station during each study. The white and black bars at the top of (a) indicate periods of day and night, respectively. Each hour of visual and acoustic efforts is depicted as vertical bars (number of calls or whales $>0$ ) or horizontal lines (number of calls or whales $=0$ ). Abscissa is shown in local time.

\section{B. Species identification}

Low frequency downsweep calls were detected and localized within $3 \mathrm{~km}$ of the anchor station during every study period (Fig. 5). Calls tended to be clustered into periods of high calling rates separated by long periods of silence, which is consistent with whales moving in and out of the $3 \mathrm{~km}$ radius around the station as well as possible diel periodicity. Whale abundance derived from the visual sightings was highly variable. Right whales were nearly always present at anchor stations 1-3, but not at station 4 . The continuous presence of right whales was not particularly surprising considering that the station locations were chosen primarily based on the initial high abundance of right whales. A large multispecies aggregation of right, sei, and humpback whales was encountered at station 3 on the afternoon of May 22, 2007, but sei and humpback whale abundance was otherwise generally low at the stations. Fin whales (Balaenoptera physalus) were sighted at the anchor stations occupied during 2007 only (including in the May 22 multispecies aggregation), but sightings were uncommon and abundance was very low. The coefficient of association between call occurrence and whale presence was highest for sei whales $(\phi$
$=0.315$; Table II) and the null hypothesis of independence was rejected only for sei whales (Fisher's exact test; $p$ $=0.016$; Table II), which strongly suggest that sei whales produce the low frequency downsweep call.

\section{Detector performance}

Manual review (visual and aural) of the recorder data from one of the MARUs deployed near anchor station 1 yielded 302 low frequency sei whale calls over the $25.5 \mathrm{~h}$ deployment. During the assisted review, all but 5 of these 302 calls $(98.3 \%)$ were detected with the preliminary kernel detector and confirmed to be low frequency sei whale calls. The preliminary kernel detector also isolated 620 additional vocalizations confirmed to be low frequency sei whale calls that were not detected during manual review of the recorder data. The use of the preliminary synthetic kernel allowed a substantial increase in sensitivity by isolating calls that were nearly impossible to recognize visually in a spectrogram, yet were clearly detectable by ear.

The performance of kernels derived from separate amplitude contours of the averaged exemplar calls was evaluated by comparing detections for a range of detection thresh- 
TABLE II. Species-specific, two-way contingency tables comparing hourly occurrence of whales from visual observations (present or absent) to occurrence of calls from acoustic observations (call or no call) within $3 \mathrm{~km}$ of the anchor stations. The accompanying coefficient of association ( $\phi$, Sokal and Rohlf, 1995) and $p$-value $(p)$ for a one-tailed Fisher's exact test of independence are provided. Only those incomplete visual survey units with whales present are included in these tallies; therefore, the total number of hourly survey units varies between species (see text).

\begin{tabular}{lccccc}
\hline \hline & Call & No call & Total & $\phi$ & $p$ \\
\hline Humpback whale & & & & & \\
Present & 1 & 11 & 12 & & \\
Absent & 5 & 48 & 53 & -0.015 & \\
Total & 6 & 59 & 65 & & \\
Right whale & & & & & \\
Present & 10 & 49 & 59 & 0.087 \\
Absent & 0 & 15 & 15 & & \\
Total & 10 & 64 & 74 & & \\
Sei whale & & & & & \\
Present & 6 & 17 & 23 & 0.016 \\
Absent & 2 & 42 & 44 & 0.315 & \\
Total & 8 & 59 & 67 & \\
\hline \hline
\end{tabular}

olds with the more than 900 confirmed calls identified by the assisted review (Fig. 6). The largest kernels (both in duration and bandwidth) performed similarly, but performance generally decreased with kernel size. Detection performance was quite good for the detector that minimized both missed calls and false detections (Fig. 7); for a threshold of 0.25, the percentage of missed calls and false detections were $13.5 \%$ and $15.3 \%$, respectively, while only two false detections were encountered for every ten true detections (Table III).

\section{DISCUSSION}

Using systematic collocated visual and acoustic observations, we documented a low frequency downsweep call pre-

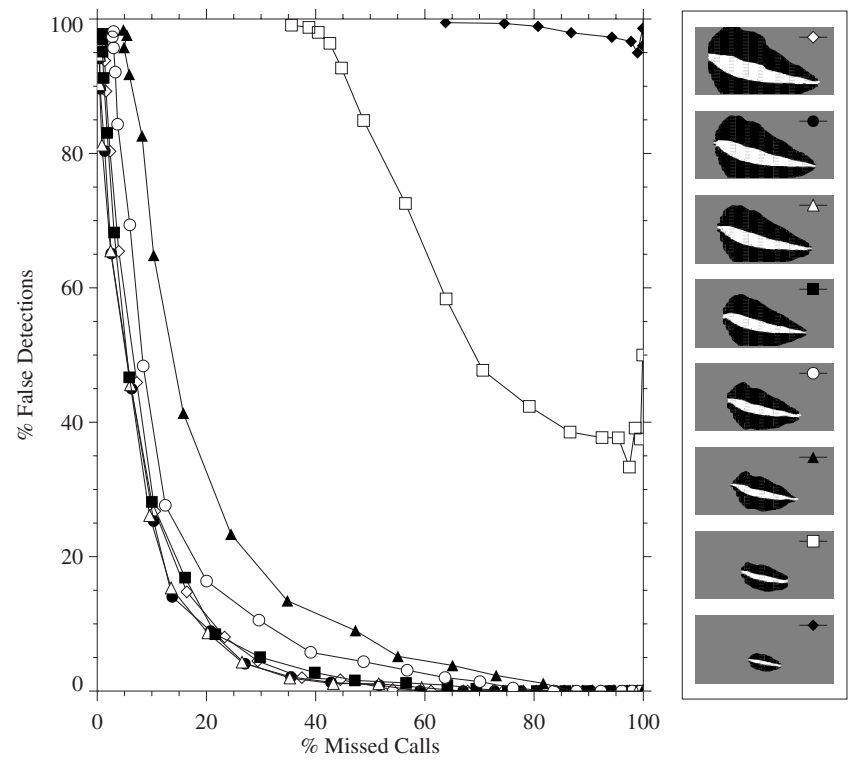

FIG. 6. Performance of each kernel detector measured by the percentages of missed calls and false detections. Kernels that minimize both missed calls and false detections (i.e., pass closest to the origin) are considered optimal for most applications. Representations of each kernel are shown at the right in frequency-time space as in Fig. 7 (the $x$-axis represents time ranging from 0 to $3 \mathrm{~s}$, the $y$-axis represents frequency ranging from 0 to $150 \mathrm{~Hz}$, and the shading indicates the sign of the kernel: white $=$ positive, black=negative, gray $=0)$. viously unreported in the Atlantic Ocean and attributed these calls to sei whales. This call was by no means uncommon; during the first anchor station study, the call was recorded on one MARU an average of 37 times/h. Baumgartner and Fratantoni (in press) observed calling rates of over 500 per hour from ocean glider deployments in the Great South Channel during May 2005. This call is present in other recent acoustic recordings from the Gulf of Maine (Van Parijs unpublished data), New England Shelf (D. Fratantoni, personal communication), mid-Atlantic Bight (J. Lynch, personal communication), and in Davis Strait between Greenland and Canada (K. Stafford, personal communication). The call is similar to a low frequency call attributed to sei whales in the Pacific Ocean by Rankin and Barlow (2007). The Pacific recordings were collected at low latitudes during late

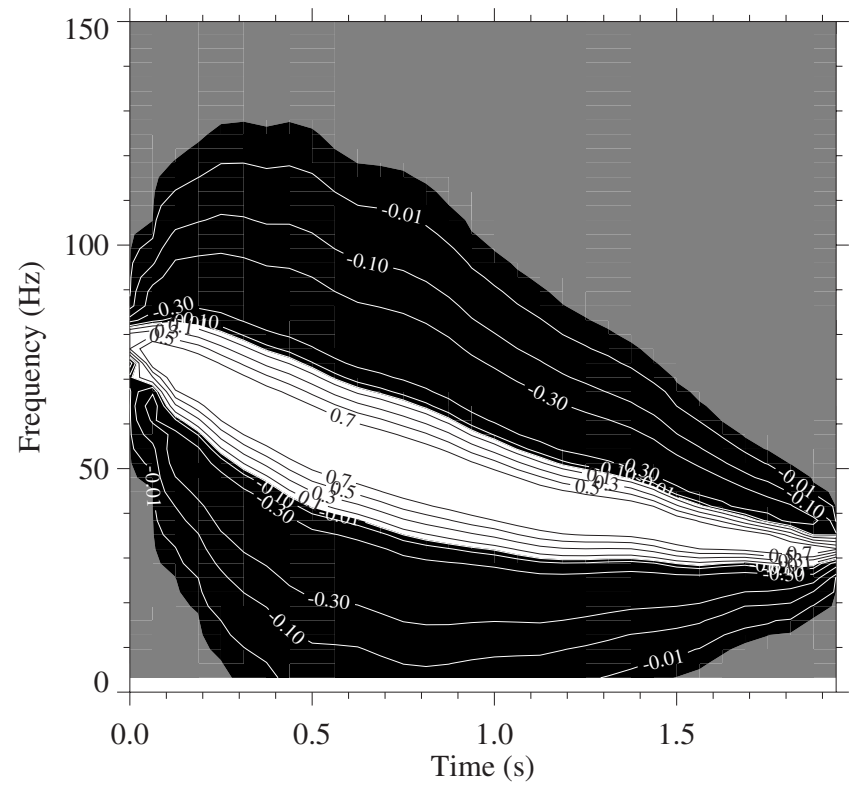

FIG. 7. Synthetic kernel with the best performance characteristics (depicted with open triangles in Fig. 6) for detecting sei whale, low frequency downsweep calls. 
TABLE III. Performance results for the optimal kernel detector (depicted with open triangles in Fig. 6). True positive indicates the number of correctly detected calls, false negative indicates the number of calls missed by the detector, and false positive indicates the number of false detections.

\begin{tabular}{cccccccc}
\hline \hline $\begin{array}{l}\text { Detection } \\
\text { threshold }\end{array}$ & $\begin{array}{c}\text { True } \\
\text { positive }\end{array}$ & $\begin{array}{c}\text { False } \\
\text { negative }\end{array}$ & $\begin{array}{c}\text { False } \\
\text { positive }\end{array}$ & $\begin{array}{c}\text { Total } \\
\text { detections }\end{array}$ & $\begin{array}{c}\text { Missed } \\
\text { calls } \\
(\%)\end{array}$ & $\begin{array}{c}\text { False } \\
\text { detections } \\
(\%)\end{array}$ & $\begin{array}{c}\text { False:True } \\
\text { detections }\end{array}$ \\
\hline 0.05 & 933 & 6 & 38739 & 39672 & 0.6 & 97.6 & 41.5 \\
0.10 & 935 & 4 & 16415 & 17350 & 0.4 & 94.6 & 17.6 \\
0.15 & 931 & 8 & 4028 & 4959 & 0.9 & 81.2 & 4.3 \\
0.20 & 882 & 57 & 738 & 1620 & 6.1 & 45.6 & 0.8 \\
0.25 & 812 & 127 & 147 & 959 & 13.5 & 15.3 & 0.2 \\
0.30 & 690 & 249 & 31 & 721 & 26.5 & 4.3 & 0.0 \\
0.35 & 533 & 406 & 6 & 539 & 43.2 & 1.1 & 0.0 \\
0.40 & 381 & 558 & 2 & 383 & 59.4 & 0.5 & 0.0 \\
0.45 & 259 & 680 & 0 & 259 & 72.4 & 0.0 & 0.0 \\
0.50 & 155 & 784 & 0 & 155 & 83.5 & 0.0 & 0.0 \\
0.55 & 87 & 852 & 0 & 87 & 90.7 & 0.0 & 0.0 \\
0.60 & 24 & 915 & 0 & 24 & 97.4 & 0.0 & 0.0 \\
0.65 & 1 & 938 & 0 & 1 & 99.9 & 0.0 & 0.0 \\
\hline \hline
\end{tabular}

fall, and when comparing these calls to previously reported midfrequency calls recorded during summer in the Atlantic and the Antarctic, Rankin and Barlow (2007) speculated that the low frequency downsweeps may be geographically distinct or only produced on the wintering grounds. If the calls recorded by both us and Rankin and Barlow (2007) serve the same function, then the occurrence of these calls on temperate feeding grounds during the spring suggests that these calls are not restricted to any region or season.

Despite our reliance on recordings collected in the presence of right and humpback whales, it is unlikely that either of these species produce the low frequency downsweep call. North Atlantic right whales make a variety of low frequency tonal and FM calls, including a higher frequency downsweep call (Parks and Clark, 2007). A considerable amount of acoustic data have been collected in the exclusive presence of right whales and from sound-recording tags attached to right whales (Matthews et al., 2001; Parks and Tyack, 2005), yet a low frequency downsweep call similar to the one described here has never been detected in those recordings ( $\mathrm{S}$. Parks, personal communication). Humpback whales make a stunning variety of sounds organized in both song and individual calls (e.g., Payne and McVay, 1971; D'Vincent et al., 1985; Clark and Clapham, 2004), including vocalizations in the $30-90 \mathrm{~Hz}$ frequency band. The rich repertoire and loquaciousness of humpback whales can certainly confound efforts to isolate and identify calls made by other species; however, our analysis indicated that the occurrence of the low frequency call was not at all related to the occurrence of humpback whales $(\phi=-0.015, \mathrm{p}=0.722$, Table II).

Because the downsweep call described here is at low frequency, FM, and produced often, we suggest that it likely functions as a contact call. Attenuation of an acoustic signal increases exponentially with the frequency; therefore, lower frequency calls can be detected at comparatively longer distances than higher frequency calls. Frequency modulation of the call further improves signal discrimination from background noise and competing sounds (Wiley and Richards, 1978). Sei whales do not tend to aggregate in tightly associ- ated groups (groups tend to be comprised of only a few animals when assessed visually; Perry et al., 1999); therefore, acoustic contact over long distances via a low frequency call may allow dispersed animals to coordinate activities such as feeding or breeding (Payne and Webb, 1971). Downsweep calls at the perimeter of the array (where localization errors are relatively small) were easily detected on all of the recorders, indicating that detection range was at least $7.5 \mathrm{~km}$ (the diameter of the area bounded by the array); although localization errors undoubtedly increased with distance from the array, maximum detection distances estimated from calls outside the array were realistically in the range $10-15 \mathrm{~km}$ and possibly as high as $20 \mathrm{~km}$.

While some of the variability in the starting frequency and duration of the calls is attributable to attenuation of higher frequency components for distant calls, subtle differences between calls were observed [Fig. 4(a)]. Variability in calls was largely a function of the start frequency; calls with higher starting frequencies tended to be longer, steeper in slope, and swept through a larger range of frequencies. The ending frequency was much less variable than the starting frequency. These characteristics suggest that the ending frequency of the call is relatively fixed, whereas the starting frequency can vary and this variation influences the duration of the call (lower starting frequencies result in shorter calls). This variation may largely be due to differences between individuals. We found that individual calls within pairs [e.g., Figs. 3(b) and 4(b)] were more similar to one another than to calls made by other whales. Although the close spatial proximity of calls produced within pairs and their similarity strongly suggests that these paired calls are produced by a single whale, it is possible that associated animals (e.g., mother and calf, and paired adults) may countercall when nearby to one another. However, the loudness of these paired calls suggests otherwise: Why would a whale produce a call that can be heard $\sim 10 \mathrm{~km}$ away when the intended listener is only, on average, $66 \mathrm{~m}$ away? If pairs are indeed produced by a single whale, then call structure may be far less variable between calls made by the same whale than between calls by 
TABLE IV. Comparisons of both call rate (CR) and call occurrence (CO) with visual abundance (VA) and visual occurrence (VO) using generalized linear models. Models with call rate as the dependent variable are Poisson regression models and those with call occurrence as the dependent variable are logistic regression models. Each drop in deviance statistic has one degree of freedom. In each case, $\beta_{1}$ indicates the nature and magnitude of the relationship between the variables, and the $p$-value $(p)$ indicates the significance of the relationship. Visual occurrence was treated as an indicator variable in the models (i.e., 0 for absent and 1 for present).

\begin{tabular}{|c|c|c|c|c|}
\hline Comparison & Model & $\beta_{1}$ & $\begin{array}{l}\text { Drop in } \\
\text { deviance }\end{array}$ & $p$ \\
\hline Call rate versus visual abundance & $\log (\mathrm{CR})=\beta_{0}+\beta_{1}(\mathrm{VA})$ & -0.0756 & 0.364 & 0.546 \\
\hline Call rate versus visual occurrence & $\log (\mathrm{CR})=\beta_{0}+\beta_{1}(\mathrm{VO})$ & 1.29 & 11.7 & 0.0006 \\
\hline Call occurrence versus visual abundance & $\operatorname{logit}(\mathrm{CO})=\beta_{0}+\beta_{1}(\mathrm{VA})$ & 0.0535 & 0.106 & 0.745 \\
\hline Call occurrence versus visual occurrence ${ }^{a}$ & $\operatorname{logit}(\mathrm{CO})=\beta_{0}+\beta_{1}(\mathrm{VO})$ & 2.00 & 6.33 & 0.0118 \\
\hline
\end{tabular}

aThis comparison is equivalent to the Fisher's exact test reported in Sec. III.

different whales. Similar observations in bottlenose dolphin vocalizations by Caldwell and Caldwell (1965) suggested that dolphins produce individually distinctive contact calls (signature whistles), and research in recent decades has provided support for this hypothesis (Smolker et al., 1993; Janik and Slater, 1998, Sayigh et al., 2007). Although no work has been published on signature contact calls in baleen whales (likely owing to the difficulties of experimental manipulation), the prevalence of individually identifiable contact calls in other taxa (reviewed in Boughman and Moss, 2003) suggests that such calls are probably used by baleen whales.

Despite these subtle differences between vocalizations, the prevalence of the downsweep call, its low frequency, and its stereotypic character make this call extremely useful for detecting the presence of vocalizing sei whales. The excellent performance of the synthetic kernel when compared to manual analysis was surprising. The automated method clearly highlighted calls that were impossible to detect visually during routine inspection of a spectrogram unless prompted to carefully review a specific time period both visually and aurally. The increased sensitivity of the automated detector not only allowed identification of faint calls, but also of calls that were missed by a reviewer because of nonoptimal spectrogram viewing parameters (e.g., contrast and brightness) or fatigue. While the automated detector works well for detecting calls when they occur, no detector (human or automated) can detect the presence of whales in an acoustic record when whales are not vocalizing. There were periods at anchor stations 3 and 4 (Fig. 5) when daytime abundances of sei whales were relatively high, yet very few or no calls were produced. During May 2005, Baumgartner and Fratantoni (in press) observed diel periodicity in the calling rates of sei whales in this same region (higher calling rates by day than night). There is some suggestion that calling rates within $3 \mathrm{~km}$ of the anchor stations during 2007 also exhibited diel periodicity, but in the opposite direction (higher calling rates by night than day). These preliminary observations are the subject of ongoing research, but clearly temporal variability in calling rates will have a profound impact on estimates of occurrence.

There is often a strong desire in passive acoustic monitoring applications to generate abundance estimates from detection data, yet the nature of the relationship between vocalization behavior and abundance has yet to be elucidated for nearly all marine mammals. For obligate callers, such as echolocating odontocetes, there is hope that vocalization rates may be correlated with abundance, but for baleen whales that vocalize primarily for social reasons, this relationship remains unclear. In our study, hourly vocalization rates of the downsweep call localized within $3 \mathrm{~km}$ of the anchor stations (treated as a Poisson process) were not correlated with sei whale abundance determined from the visual surveys, nor was the hourly occurrence of calls related to sei whale abundance (Table IV). Both call rate and call occurrence were significantly related to sei whale occurrence, which simply indicates that the odds of detecting a call as well as the rate of calling increase when sei whales are present (a rather self-evident result when one accepts that sei whales produce the downsweep call). From these observations, it is clear that the abundance of sei whales cannot be predicted from vocalization rates at hourly time scales. Even occurrence, although strongly related to vocalization rates and the occurrence of calls, is not perfectly predicted by vocalizations. Accurate detection of a vocalization is certainly conclusive evidence of the presence of a whale, but silence is not always indicative of an absence of whales; in our study, sei whales were present during 17 (29\%) of the 59 hourly periods during which calls were not detected within $3 \mathrm{~km}$ of the anchor stations (Table II). Interestingly, there were two hourly periods when sei whale calls were detected, yet no sei whales were seen. In each of these periods, the calls were likely produced by a single animal (based on the pattern of localizations: clumped within $250 \mathrm{~m}$ of one another in one case, and in a linear sequence indicative of a traveling whale in the other) approximately $2 \mathrm{~km}$ from the ship during the observing period. Visual observations are clearly the only reliable method to confirm the identity of calling whales, but not all vocalizing whales, particularly single whales, can be seen and identified using the methods employed in this study.

Comparisons between the occurrence of localized low frequency downsweep calls and the presence of baleen whales around the anchor stations provided strong evidence that sei whales produced these calls. A relatively large dataset of collocated visual and acoustic observations (70 h) was required to successfully attribute the downsweep call to a particular species because of the high abundance and cooc- 
currence of three potential sources: right, sei, and humpback whales. Previous studies have relied on relatively short-term recordings of a particular call in the presence of only a single species for attribution of the call to that species; however, this approach precludes attribution in areas frequented by several species, is susceptible to confounding by audible animals of other species that are not in visual range, and can be thwarted by temporal variability in calling behavior (i.e., encounters with silent whales prevent attribution of their calls). Longer collocated visual and acoustic time series, while expensive and not particularly glamorous to collect, are critical to the successful identification of species-specific calls. Such information will allow progressive acoustic studies, which (1) utilize a larger suite of calls per species, (2) characterize calling variability (in terms of the types of vocalizations) and the environmental and social context of the calls, and (3) describe the community composition of the vocalizing animals.

\section{ACKNOWLEDGMENTS}

We are indebted to the many observers that collected the visual sighting data for this study, including Ingrid Biedron, Shonda Gaylord, Nicole Gilles, Elizabeth Josephsen, Betty Lentell, Nadine Lysiak, Sarah Mussoline, John Nicolas, Richard Pace, Melissa Patrician, David Potter, and Elizabeth $\mathrm{Vu}$. We are also grateful for the able help of the captain, officers, and crew of the NOAA R/V Albatross IV for their help at sea. Cornell University Laboratory of Ornithology's Bioacoustics Research Program graciously made the MARUs available to us for lease. Fred Serchuk provided helpful criticisms of this paper, as did two anonymous reviewers. Funding was provided by the NOAA National Marine Fisheries Service and the WHOI Ocean Life Institute.

Baumgartner, M. F., and Fratantoni, D. M. (2008). "Diel periodicity in both sei whale vocalization rates and the vertical migration of their copepod prey observed from ocean gliders," Limnol. Oceanogr. (in press).

Baumgartner, M. F., Fratantoni, D. M., and Clark, D. W. (2006). "Investigating baleen whale ecology with simultaneous oceanographic and acoustic observations from autonomous underwater vehicles," Eos Transactions, American Geophysical Union 87(36), Ocean Sciences Meeting Supplement, Abstract OS24E-05, Honolulu, Hawaii, 20-24 February.

Baumgartner, M. F., Freitag, L., Partan, J., Ball, K., and Prada, K. (2008). "Tracking large marine predators in three dimensions: The real-time acoustic tracking system," IEEE J. Ocean. Eng. (in press).

Boughman, J. W., and Moss, C. F. (2003). "Social sounds: Vocal learning and development of mammal and bird calls," in Acoustic Communication, edited by A. M. Simmons, A. N. Popper, and R. R. Fay (Springer, New York), pp. 138-224.

Caldwell, M. C., and Caldwell, D. K. (1965). "Individualized whistle contours in bottlenose dolphins (Tursiops truncatus)," Nature (London) 207, 434-435.

Clark, C. W., and Clapham, P. J. (2004). "Acoustic monitoring on a humpback whale (Megaptera novaeangliae) feeding ground shows continual singing into late spring," Proc. R. Soc. London, Ser. B 271, 1051-1057.

Croll, D. A., Clark, C. W., Acevedo, A., Tershy, B., Fores, S., Gedamke, J., and Urban, J. (2002). "Only male fin whales sing loud songs," Nature (London) 417, 809.

Darling, J. D., Jones, M. E., and Nicklin, C. P. (2006). "Humpback whale songs: Do they organize males during the breeding season?," Behaviour 143, 1051-1101.

D'Vincent, C. G., Nilson, R. M., and Hanna, R. E. (1985). "Vocalization and coordinated feeding behavior of the humpback whale in southeastern Alaska," Sci. Rep. Whales Res. Inst. 36, 11-47.

Flinn, R. D., Trites, A. W., Gregr, E. J., and Perry, R. I. (2002). "Diets of fin, sei, and sperm whales in British Columbia: An analysis of commercial whaling records, 1963-1967," Marine Mammal Sci. 18, 663-679.

Foy, W. H. (1976). "Position-location solutions by Taylor-series estimation," IEEE Trans. Aerosp. Electron. Syst. 12, 187-194.

Fratantoni, D. M., and Baumgartner, M. F. (2005). "AUV-based physical, biological, and acoustic observations in support of marine mammal ecology studies," International Ocean Research Conference, 6-10 June (The Oceanography Society, Paris, France).

Freitag, L., Johnson, M., Grund, M., Singh, S., and Preisig, J. (2001). "Integrated acoustic communication and navigation for multiple UUVs," Proceedings of MTS/IEEE OCEANS 2001, Vol. 4, pp. 2065-2070.

George, J. C., Zeh, J., Suydam, R., and Clark, C. (2004). “Abundance and population trend (1978-2001) of western Arctic bowhead whales surveyed near Barrow, Alaska," Marine Mammal Sci. 20, 755-773.

Heimlich, S. L., Mellinger, D. K., and Nieukirk, S. L. (2005). "Types, distribution, and seasonal occurrence of sounds attributed to Bryde's whales (Balaenoptera edeni) recorded in the eastern tropical Pacific, 1999-2001," J. Acoust. Soc. Am. 118, 1830-1837.

Hjort, J., and Ruud, J. T. (1929). "Whales and plankton in the North Atlantic," Conseil Permanent International pour l'Exploration de la Mer. Rapports et Procès Verbaux des Réunions, Vol. 56, pp. 5-123.

Janik, V. M., and Slater, P. B. (1998). "Context-specific use suggests that bottlenose dolphin signature whistles are cohesion calls," Anim. Behav. 56, 829-838.

Johnson, M., Madsen, P. T., Aguilar Soto, N., and Tyack, P. (2006). "Foraging Blainville's beaked whales (Mesoplodon densirostris) produce distinct click types matched to different phases of echolocation," J. Exp. Biol. 209, 5038-5050.

Kawamura, A. (1974). "Food and feeding ecology in the southern sei whale," Sci. Rep. Whales Res. Inst. 26, 25-144.

Knowlton, A. R., Clark, C. W., and Kraus, S. D. (1991). "Sounds recorded in the presence of sei whales, Balaenoptera borealis," Abstract in the Ninth Biennial Conference on the Biology of Marine Mammals, Chicago, IL, p. 40.

Madsen, P. T., Payne, R., Kristiansen, N. U., Wahlberg, M., Kerr, I., and Moehl, B. (2002). "Sperm whale sound production studied with ultrasound time/depth-recording tags," J. Exp. Biol. 205, 1899-1906.

Matthews, J. N., Brown, S., Gillespie, D., Johnson, M., McLanaghan, R., Moscrop, A., Nowacek, D., Leaper, R., Lewis, T., and Tyack, P. (2001). "Vocalisation rates of the North Atlantic right whale (Eubalaena glacialis)," J. Cetacean Res. Manage. 3, 271-282.

McDonald, M. A., Hildebrand, J. A., Wiggins, S. M., Thiele, D., Glasgow, D., and Moore, S. E. (2005). "Sei whale sounds recorded in the Antarctic," J. Acoust. Soc. Am. 118, 3941-3945.

Mellinger, D. K., and Clark, C. W. (2000). "Recognizing transient lowfrequency whale sounds by spectrogram correlation," J. Acoust. Soc. Am. 107, 3518-3529.

Mellinger, D. K., Nieukirk, S. L., Matsumoto, H., Heimlich, S. L., Dziak, R. P., Haxel, J., Fowler, M., Meinig, C., and Miller, H. V. (2007). "Seasonal occurrence of North Atlantic right whale (Eubalaena glacialis) vocalizations at two sites on the Scotian Shelf," Marine Mammal Sci. 23, 856867.

Mizroch, S. A., Rice, D. W., and Breiwick, J. M. (1984). "The sei whale, Balaenoptera borealis," Mar. Fish. Rev. 46, 25-29.

Oleson, E. M., Calambokidis, J., Burgess, W. C., McDonald, M. A., LeDuc, C. A., and Hildebrand, J. A. (2007). "Behavioral context of call production by eastern North Pacific blue whales," Mar. Ecol.: Prog. Ser. 330, 269284.

Parks, S. E., and Clark, C. W. (2007). "Acoustic communication: Social sounds and the potential impacts of noise," in The Urban Whale: North Atlantic Right Whales at the Crossroads, edited by S. D. Kraus and R. M. Rolland (Harvard University Press, Cambridge, MA), pp. 310-332.

Parks, S. E., and Tyack, P. L. (2005). "Sound production by North Atlantic right whales (Eubalaena glacialis) in surface active groups," J. Acoust. Soc. Am. 117, 3297-3306.

Payne, R., and McVay, S. (1971). "Songs of humpback whales," Science 173, 585-597.

Payne, R., and Webb, D. (1971). "Orientation by means of long range acoustic signaling in baleen whales," Ann. N.Y. Acad. Sci. 188, 110-142.

Perry, S. L., DeMaster, D. P., and Silber, G. K. (1999). "The great whales: History and status of six species listed as endangered under the U.S. Endangered Species Act of 1973," Mar. Fish. Rev. 61, 1-74.

Rankin, S., and Barlow, J. (2007). "Vocalizations of the sei whale Balaenoptera borealis off the Hawaiian Islands," Bioacoustics 16, 137-145. 
Sayigh, L. S., Esch, H. C., Wells, R. S., and Janik, V. M. (2007). "Facts about signature whistles of bottlenose dolphins, Tursiops truncates," Anim. Behav. 74, 1631-1642.

Smolker, R. A., Mann, J., and Smuts, B. B. (1993). "Use of signature whistles during separations and reunions by wild bottlenose dolphin mothers and infants," Behav. Ecol. Sociobiol. 33, 393-402.

Sokal, R. R., and Rohlf, F. J. (1995). Biometry, 3rd ed. (W. H. Freeman, New York).

Stafford, K. M., Nieukirk, S. L., and Fox, C. G. (2001). "Geographic and seasonal variation of blue whale calls in the North Pacific," J. Cetacean Res. Manage. 3, 65-76.

Stimpert, A. K., Wiley, D. N., Au, W. W. L., Johnson, M. P., and Arsenault, R. (2007). "'Megapclicks': Acoustic click trains and buzzes produced during night-time foraging of humpback whales (Megaptera novaeangliae),'
Biotechnol. Lett. 3, 467-470.

Thompson, T. J., Winn, H. E., and Perkins, P. J. (1979). "Mysticete sounds," in: Behavior of Marine Animals, Vol. 3: Cetaceans, edited by H. E. Winn and B. L. Olla (Plenum, New York), pp. 403-431.

Watkins, W. A., and Schevill, W. E. (1971). "Four hydrophone array for acoustic three-dimensional location," Technical Report No. 71-60, Woods Hole Oceanographic Institution.

Wiley, R. H., and Richards, D. G. (1978). "Physical constraints on acoustic communication in the atmosphere: Implications for the evolution of animal vocalizations," Behav. Ecol. Sociobiol. 3, 69-94.

Zimmer, W. M. X., Johnson, M., Madsen, P. T. M., and Tyack, P. L. (2005). "Echolocation clicks of free-ranging Cuvier's beaked whales (Ziphius cavirostris)," J. Acoust. Soc. Am. 117, 3919-3927. 